\title{
Analysis on Pore-Forming Pouring Pile Construction Technology of House Building Project
}

\author{
Lili Hu \\ China West Normal University, Nanchong, China \\ Email: mlbsabc@sina.com
}

How to cite this paper: Hu, L.L. (2016) Analysis on Pore-Forming Pouring Pile Construction Technology of House Building Project. Open Journal of Civil Engineering, 6, 697-703.

http://dx.doi.org/10.4236/ojce.2016.64056

Received: June 20, 2016

Accepted: September 27, 2016

Published: September 30, 2016

Copyright $\odot 2016$ by authors and Scientific Research Publishing Inc. This work is licensed under the Creative Commons Attribution International License (CC BY 4.0).

http://creativecommons.org/licenses/by/4.0/

\section{(c) (†) Open Access}

\begin{abstract}
Compared with the in-place pile, the pore-forming pouring pile is more simple and convenient, with a wider range of construction. In the actual construction process, it is able to pass through complex bottom layer and water layer underground without very high requirements in equipment. The actual bearing capacity of single pile is very strong, so that it can be better to adapt to the actual needs of different scales or the different geological conditions in building. And it has been promoted and used greatly in building construction work [1]. This paper introduces the concept of the pore-forming pouring pile technology, analyzes the pore-forming construction technology and the pile construction technology, then talks about prevention problems of the pore-forming pouring pile construction in House Building Project, at last draws a conclusion that the pore-forming pouring pile technology is the most basic construction technology and is the most effective and convenient way of construction.
\end{abstract}

\section{Keywords}

Building Construction, Pore-Forming Pouring Pile, Normal Circulation

Rotary Drilling Holes Forming Technology

\section{Introduction}

The pressure of social economy development increasingly urges the unceasing increase of people's material life level. The population also exhibits a very strong agglomeration effect. The pace of urbanization development is increasing, in addition, more and more pressure of living prompted the city to build some high buildings with more storeys with the aim to effectively alleviate the population living pressure. Due to the design, 
technology, raw materials and supervision work of the housing building construction are imperfect, which will lead to the main crack of the wall, even building collapse and other problems in the following construction. What's worse, it seriously influences the use function and the actual construction life of the building, which causes great threat to the life and property of the building army and people. Therefore, it needs to combine with the building foundation construction process to comprehensively control the construction technology, and also needs to control the actual construction work according to the difference of construction conditions, in order to completely dip reinforced cage work into the hole after the work of forming holes and finally finish the concrete pouring work in the aggregate housing construction work. In short, in the construction of housing construction work, it needs to pay attention to the application of bored pile construction technology and adhere to the scientific and reasonable methods, to provide protection and enhance the quality of housing construction [2].

\section{Summary of the Pore-Forming Pouring Pile Technology}

\subsection{The Concept of the Pore-Forming Pouring Pile Technology}

In the construction of housing construction, the technology of the pore-forming pouring pile plays an important role. The technology of the pore-forming pouring pile actually is using the construction mechanical drilling, artificial mining or soil squeezing pipe in terms of construction in the process, so as to form a pile in the building foundation. The pile hole and concrete pouring are used to set reinforcement cage and ponder the hole, which is the most widely used and the most effective perfusion technique of foundation pile currently. Due to there are some differences in the hole forming way, the cast-in-place pile is mainly divided into the immersed tube, digging holes and hole type. And due to there are differences in the formation of piles, finally the construction method of the pore-forming pouring pile is formed.

\subsection{The Characteristics of the Pore-Forming Pouring Pile Technology}

In the process of building construction, compared with other pile, the noise of the poreforming pouring pile is relatively smaller and its practical range of vibration effect is better, also, the influence on the surrounding environment of construction is relatively fewer, so it has been widely used. In addition, the technology of the pore-forming pouring pile is advanced and can be poured in pile column with larger diameter. It can be used to better meet the needs of the construction of the housing construction, with a wider range in the actual application and better application results [3]. In the housing construction process, it will inevitably exist some loopholes by apply the pore-forming pouring pile, which are influent the actual effect of construction. And the foundation bearing capacity directly affects the construction quality. It will directly affect the quality of housing foundation construction if it can't guarantee the quality of construction, or the bearing capacity of pile foundation fails to reach the actual requirements. There is a certain degree of difficulty in controlling the quality of concrete because of the technology of the pore-forming pouring pile often selects the slurry perfusion, which 
will affect the actual construction effect.

\section{Analysis of the Pore-Forming Construction Technology}

\subsection{Embedded Pile Casing}

In the process of building construction, pile casing plays a very important role. It has a very important role on the fixed pile holes position, can effectively prevent the inflow of ground water, and effectively prevent the collapse problem. It needs to timely guide drill direction when forming the hole. In the process of selecting raw material for the support tubes, it needs to choose steel plates with the thickness of $4 \mathrm{~mm}$ to $8 \mathrm{~mm}$, and ensure the diameter of drill diameter is in $100 \mathrm{~mm}$ to $200 \mathrm{~mm}$, while the top surface needs to be higher ground for $0.4 \mathrm{~m}$ to $0.6 \mathrm{~m}$. In addition, it needs to ensure that there are one to two overflow holes above the pile casing. It needs to prepare for embedding the pile casing, which is to dig hole pile surface coating, and then embedding the pile casing into the soil with depth of more than $1 \mathrm{~m}$, especially should be embedded more than $1.5 \mathrm{~m}$ in the sand. Its height also needs to meet the height requirements of the liquid level of the mud in the hole. At the same time, the mud surface of inner hole needs to remain in the high water line more than $1 \mathrm{~m}$. In the process of digging shield for the pile casing burying, it needs to guarantee the hole diameter is larger the diameter of pile casing' diameter about 1 meter. At the same time retaining position deviation of tube center and center of pile can't be more than $50 \mathrm{~mm}$. in the It needs to clay to the outer side of the pile casing after mastering the position, and then layered work for the solid foundation [4].

\subsection{The Normal Circulation Rotary Drilling Holes Forming Technology}

The normal circulation rotary can reduce the rate of return when forming holes. It carries soil with relatively small diameter so the ability of slag is relatively weak, which may cause very serious rock repetitive crushing phenomenon. So it is more suitable for silt, soil and sand. In the holes forming work, it needs to ensure that the holes diameter of the pile is not more than $1000 \mathrm{~mm}$, and the depth also needs to effective control. It mainly use the flushing fluid volume, drilling pressure or the speed, which requires to ensure that the amount of flushing fluid is sufficient, so as to provide protection for the normal circulation rotary. As for the sandy soil, most of them choose hard alloy bit with speed control unit from 40 to 80 . As for the harder soil, it can be properly adjusted slow speed. As for choosing steel grain drill drilling method, then the speed can be control in the units from 5 to $12 \mathrm{EU}$ and the large pile can select the minimum value while the small pile can select the maximum value. According to the special difference, it can choose different speed and drilling method, which requires a comprehensive assessment of the actual working environment in order to improve the efficiency of the actual work [5].

\subsection{Grasping Holes}

In the process of housing construction, grasping hole plays a very important role. It 
needs make a comprehensive analysis for the weight block and movable catch within the cone and continuous adjustment for the actual construction after the completion of the construction work or the building has attend to a certain height. The claw will open and bit deep into the soil when the winding engine brake remains open, which requires the use of a free fall way to control the whole construction work. At the same time to lift the bit, when the catch plate is at the closed state, so it can enhance the overall height of the grasp, as well as remove the dregs, to complete the work of the grabbing holes through this cycle. In the work of grasping holes, when the holes diameter is control in the $450 \mathrm{~mm}$ to $600 \mathrm{~mm}$, the holes depth should be controlled at about $10 \mathrm{~m}$. It is mainly used in the foundation with hard crops, such as gravel, clay and pebbles and so on.

\subsection{Holes Cleaning}

Replacement method, also known as the slurry method, is a way that using new mixing mud to replace the mud in the holes bottom, which is the way to complete the holes cleaning work through the use of circulating mud. The weight of mud needs to be controlled in 115 to 125 after complete the hole cleaning work. In the process of slurry sampling, it needs to select the position in the bottom of the hole $2 \mathrm{~cm}$ to $5 \mathrm{~cm}$, the actual sampling effects are better. The application of replacement method is relatively wide, also it can be used in the construction work of the holes wall with poor quality, such as the holes wall of clay or silt, the hole cleaning effect is relatively good. It needs to complete the work strictly in accordance with the relevant standards, in the hole to remove mud in the process of holes cleaning. As for the removal of mud in the hole, it doesn't appear to coarse feeling by touch, then it can be sure that mud density of the hole bottom within $500 \mathrm{~mm}$ did not reach to 1.25 . In addition, it needs to check the sediment thickness in the bottom of holes before pouring concrete work, to ensure that the sediment thickness conforms to the relevant work standards, and provide a guarantee for the safety of construction.

\section{Analysis of Pile Construction Technology}

\subsection{Production and Installation of Reinforcing Steel Bar}

Combined with the actual situation of the pile to make the reinforcing cages and needs to ensure the pile length is about ten meters. The anchorage length of reinforcement cages need to control in ten meters, which can make according to the actual situation. It needs to ensure the joints of the reinforcement cages are staggered and the space is not more than $70 \mathrm{~cm}$, and also needs to weld the reinforced skeleton for protection per every 2 meters, which can reduce the size error of steel reinforcement cages as far as possible. It can install steel cages according to the preset program after passing the acceptance of drilling. It needs to choose the suitable lifting points during lifting, also needs to take certain measures to prevent the deformation of reinforcing cage.

\subsection{Concrete Underwater Casting}

In the process of the concrete underwater pouring, most of them choose catheter me- 
thod. And it needs to ensure that the concrete strength can't be less than C20, gap degree needs to control at $18 \mathrm{~cm}$ to $22 \mathrm{~cm}$. It needs to guarantee to make closed type hydraulic test in assembly work and ball work, and ensure the test pressure is from 0.6 to 1 without water leakage and can be put to use before using a catheter. In the process of pouring concrete, it needs to use the elevator to suspension funnel and catheter. It needs to place into the riser pipe plug after reaching the bottom hole, then injecting concrete into the conduits, and guarantee the catheter from the ground under about $300 \mathrm{~mm}$, then cut in the conduit bolt sling quickly, so the concrete weight will be strong enough to push the ball plug whereabouts and reach the basement, showing a diffuse phenomenon. The concrete can form a retarding soil on the function of the catheter, which can reduce the catheter to base $100 \mathrm{~mm}$ to $200 \mathrm{~mm}$. The guide tube can be controlled according to the actual working procedure of the concrete, and the concrete outside the tube will also rise due to extrusion, with the increasing of concrete surface to enhance the catheter constantly.

\subsection{Operation Technology of Pouring the Retarding Soil}

It needs to know that the actual amount of the concrete and holes bottom height, height of the concrete surface and pile holes diameter and mud density occupies a very close correlation in the first concrete work. In the first concrete work, the quantity of the concrete is increase as the diameter increases, but due to the volume of concrete is relatively large, it needs to spend a lot of time to stir and prone to segregation phenomenon, and easy to make poor workability during the up and down in prone. Therefore, perfuse resistance increase and the catheter easily clogged with concrete, even funnel will residual concrete, which increase the lifting equipment pressure. Therefore, in the construction process it needs to increase the equipment capacity, so the reinforced concrete can quickly enter the funnel and then open the catheter. It can effectively solve the problem of insufficient capacity through the hoister to close the funnel, so that concrete can also fell to the bottom of the hole, which can provide a guarantee for the subsequent irrigation work. In short, in the process of consolidation of concrete perfusion, it needs to combine the actual situation of soil to choose a more effective way of filling in order to provide protection for the construction quality.

\section{Analysis on Prevention Problems of the Pore-Forming Pouring Pile Construction in House Building Project}

\subsection{Possible Problems in Building Construction}

1) The problems of the hole bottom layer and preventive measures

The holes bottom layers, is the residual slag at the bottom of the hole which may lead to the sediment into foot holes slag after, or caused wall of bottom holes collapse and makes the soil to landing. The reason is that it doesn't pay attention to cleaning work in holes lead to low clearance holes on it. After the completion of the holes cleaning, it may cause that slurry concentration is reduced or in placement of reinforcing cage, pouring concrete collision to the holes wall, which causing the collapse hole in the 
earth. Therefore, in the actual process of housing construction, it needs to pay attention to the holes cleaning work, special attention must be paid to the slurry concentration and the changes in holes water level. It also needs to know the importance of holes wall protection in the actual construction work.

2) Mud or soft interlayer

The mud and soft interlayer is that the clay mixed into the pile retarding soil in the perfusion work or mud with the phenomenon of the floating foam slurry, so there is a soft interlayer. In the process of retarded soil perfusion, because the pipe is buried too shallow or the holes wall collapse and other issues such as the lack of concrete, the mud will be sprayed over so that it will be incorporated into the concrete. Therefore, it is necessary to pay special attention to the elevation changes on the concrete surface. At the same time, it needs to keep the elevation changes catheter in buried concrete in order to ensure to build concrete after the placement of reinforcing cage within four hours [6].

\subsection{Notices for Pore-Forming Pouring Pile Construction}

In the working process of the pile casing embedded, it needs to ensure the soil layer of impermeable adhere to the principle that it always keep deep enough. It needs to improve the density and viscosity of slurry and annual if it can't be buried to depth, and it needs a slow turn in drilling process, which can improve the thickness of the holes wall soil and prevent the slurry leakage. After the completion of the opening holes work, it needs to adhere to work day and night, always pay attention to the quality of the mud to ensure the mud elevation in the pile casing higher the underground water level for 2 meters. As for holes stop drilling for long time, it needs to increase the detection work of the relative density and the relative viscosity, and remove the accidents in the course as far as possible, as well prevent the problem of the holes collapse. In drilling work, if there are following phenomenon that the mud level overflow from the pile casing and sag, bubbles and other issues, especially the drilling rig working load increasing, then it requires to consider the problem of hole collapse. It needs to make sure the responsibilities of each department and remove the reasons and location timely to take targeted and effective measures to avoid the problems continue to happen after the collapse of the holes. As for the soil that is soft and sticky viscosity, it requires to pay attention to improve the mud performance. And do the export equipment inspection work for drill pipe and drill blasting, and effective control the speed, to avoid paste drilling. In addition, it needs to check the drill stationary, inspect the degree of displacement for the drill frame timely and measure the inclination of the drill pipe before the construction, and needs to repeatedly scan the working space with inclination, and then adjust the work progress of the drilling ruler with the aim to avoid inclined hole. When the drill pipe is relatively large swing, it is required to stick to the rig operation is normal, but also need to control the speed to avoid the problem of space expansion. From the hole cleaning to the concrete casting, it needs to pay attention to know whether the mud surface elevation and the bottom of the reinforcement cage are straight, taking into account the work of slurry and steel reinforcement cage, so that it can effectively ensure the actual construction work [7]. 


\section{Conclusion}

In the work of housing construction, the technology of the pore-forming pouring pile is the most basic construction technology. It has a very important influence on the whole construction and directly impacts the quality of the actual construction. It needs to pay attention to the engineering quality supervision and management work, as well as comprehensively control the construction quality in the process of actual construction. It also requires putting forward effective preventive measures in view of the problems that may exist in the housing construction and control engineering construction condition in order to improve the quality of the housing construction. As the most effective and convenient way of construction, the technology of the pore-forming pouring pile has been widely used and generally recognized by the people, which requires strictly regulating the construction process and paying attention to the work of supervision and management to discover the problems that may exist in the construction process. What's more, it needs to avoid potential problems as far as possible and improve the quality of the actual management work in view of providing the quality of the housing construction.

\section{References}

[1] Wang, T.T. (2014) Construction Engineering Technology and Design. Elaborate on the Key Points of Construction Quality Control of Bored Pile in Housing Construction. No. 19, 21-22.

[2] GanRunqingGan, R.Q.(2013) Urban Architecture Theory Research: Electronic Edition. Discussion on the Construction Technology of the Pore-forming Pouring Pile for Housing Construction. No. 28, 12-13.

[3] Dong, L.Z. (2013) Urban Construction Theory Research, Electronic Edition. The Construction of the Pore-forming Pouring Pile in Housing Construction. No. 19, 13-15.

[4] Pei, C.M. (2015) Construction Engineering Technology and Design. Discussion on the Construction Technology of the Pore-forming Pouring Pile in Housing Construction. No. 22, 31-33.

[5] Wang, C.H. (2014) Urban Construction Theory: Electronic Edition. Discussion on the Construction Technology of the Pore-forming Pouring Pile in Housing Construction. No. 21, 12-13.

[6] Sawant, V.A. and Chore, H.S. (2010) Building Frame-Pile Foundation-Soil Interactive Analysis Using 3-D FEM. Journal of Structural Engineering (JoSE), 36, 318-325.

[7] Polous, H.G. (1968) Analysis of Settlement of Pile Groups. Géotechnique, 18, 449-471. http://dx.doi.org/10.1680/geot.1968.18.4.449 
Submit or recommend next manuscript to SCIRP and we will provide best service for you:

Accepting pre-submission inquiries through Email, Facebook, LinkedIn, Twitter, etc. A wide selection of journals (inclusive of 9 subjects, more than 200 journals)

Providing 24-hour high-quality service

User-friendly online submission system

Fair and swift peer-review system

Efficient typesetting and proofreading procedure

Display of the result of downloads and visits, as well as the number of cited articles

Maximum dissemination of your research work

Submit your manuscript at: http://papersubmission.scirp.org/

Or contact ojce@scirp.org 